\title{
Comprehensive Utilization of Water in Underground Metal Mine
}

\author{
Xianzhi Tan ${ }^{1}$, Song Jiang ${ }^{2 *}$ and Minjie Lian $^{3}$ \\ ${ }^{1}$ Sinosteel Wuhan safety and Environmental Protection Research Institute, Hubei, 430081, China \\ ${ }^{2}$ Department of Management, Xi'an University of Architecture and Technology, Shaanxi, 710055, China \\ ${ }^{3}$ Sinosteel Mining Co., Ltd, Beijing, 100080, China
}

\begin{abstract}
The ground water heat pump system lades underground hot water which can be heated or cooled by heat exchanger in water source heat pump air conditioner. This system replaces the model of heating of air-conditioning by refrigerator and boiler. In this paper, the formation conditions of hot water energy in Shan Dong are analyzed in order to achieve the purpose of energy conservation and emissions reduction by taking full advantage of water resources such as water pouring and return water of beatification during the productive process of underground metal mine. In order to analyze the issue better, the paper points out some ways and methods for geothermal water often used in underground metal mine. This paper also presents the advantages of the technology of water source heat pump that is applied into underground metal mine. Here is a case study of comprehensive utilization of water source in a certain underground metal mine in Ji Ning. This mine, according to its own actual situation, designs heat pump heat exchange system which is used for indoor heating of buildings and bath for staff. It turns out that the system can save $23 \%$ water per year, cut down 3.303 million KW electric energy, and reduce 4160t emission of carbon dioxide. It is concluded that the technology of water source heat pump has broad application prospects in underground metal mine. Therefore, the results show that it is an ideal way to change the present structure of cooling and heating source in metal mine.
\end{abstract}

Keywords: water source heat pump, metal mine, comprehensive utilization, sustainable development, energy conservation, emissions reduction

\section{Introduction}

In recent years, overuse of fossil fuels has posed a grave threat onto the environment, which makes renewable energy a more important status in energy structure. Development and utilization of renewable energy has become an important direction. Water source heat pump technology is to use solar energy stored in water as cold/heat source to convert energy. Currently, this technology has been widely used in some advanced countries. However, due to facers of implementation technology and component costs, there is still a gap in water source heat pump technology between China and these advanced countries. According to (Blum et al 2011) that after in-depth study, water source heat pump technology has developed rapidly in China recently, and the gap is gradually reduced. Groundwater source heat pump system as a kind of high efficiency, energy-saving and environmentally friendly technology in recent years, more and more get the people's attention. At the same time, its practical application has also been rapid development. Based on ( $\mathrm{Ni}$ et al 2015) that According to the relevant departments of the prediction, the technology will become the 21 st century the most efficient heating and cooling technology.

* Corresponding Author: S. Jiang, jiangsong925@163.com, phone: +86 15991802660

Copyright @ 2017 Canamaple Academia Services, http://press.camdemia.ca

\section{Introduction of Water Source Heat Pump System}

It is reported (Hakkaki et al 2015) that as natural phenomenon, the water can spontaneously flow from high place to lower place, and the heat can also run from the high temperature side to the lower temperature side.

Water source heat pump is a technology that takes advantage of solar energy and geothermal energy absorbed from shallow water of the earth's surface such as groundwater, river and lake to generate. It employs heat pump principle to realize the transformation from low-order heat energy to high-order heat energy via few inputs of high-order electric energy. If the shallow waters such as underground water under $1000 \mathrm{~m}$ of the earth's surface, rivers, lakes, and seas, absorb an amount of radiant energy of the Sun, which makes the temperature of water stable. It is reported (Sarbu and Sebarchievici 2014) that in summer, the water source heat pump can transfer the heat of buildings to the source of water can carry away heat efficiently due to the low temperature of water. While in winter, the water source heat pump extracts energy from water and transports it to buildings after increasing temperature through air or water taken as cooling medium. Generally speaking, when the water source heat pump consumes $1 \mathrm{~kW}$ energy, the users can get $4 \mathrm{~kW}$ energy. 


\subsection{System working principle}

The aquifer thermal energy storage system integrated underground water heat pump is shown in Figure 1. Liu (2009) said that using underground water as the heating and cooling resources for the heat pump; and at the same time, waste heating or cooling was re-injected into underground to gain seasonal energy storage. The total heating load is $366.6 \mathrm{~kW}$ and cooling load is $488.4 \mathrm{~kW}$ of this system. Two wells with depth of $210 \mathrm{~m}$ were drilled. The distance between wells is $50 \mathrm{~m}$. Well number one (1) is the production well and Well number two (2) is injection well when heating, underground water is pumped into the evaporator from 1\# well, in evaporator, cryogenics R22 abstract heat from underground water and boils off, then the temperature of the underground water lowered and was reinjected into underground by $2 \#$ well, the cold water was stored around 2\# well, which will be used in the summer. When cooling, the re-injected cold water was extracted from 2\# well and entered into condenser, underground water absorbed discharge heat in condenser and then temperature rise, then hot water outflow from condenser and was reinjected into underground by $1 \#$ well, the hot water was stored around 1\# well, which will supply high temperature water for the heat pump in winter. In cooling mode, $2 \#$ well is the production well and $1 \#$ well is the re-injection well.

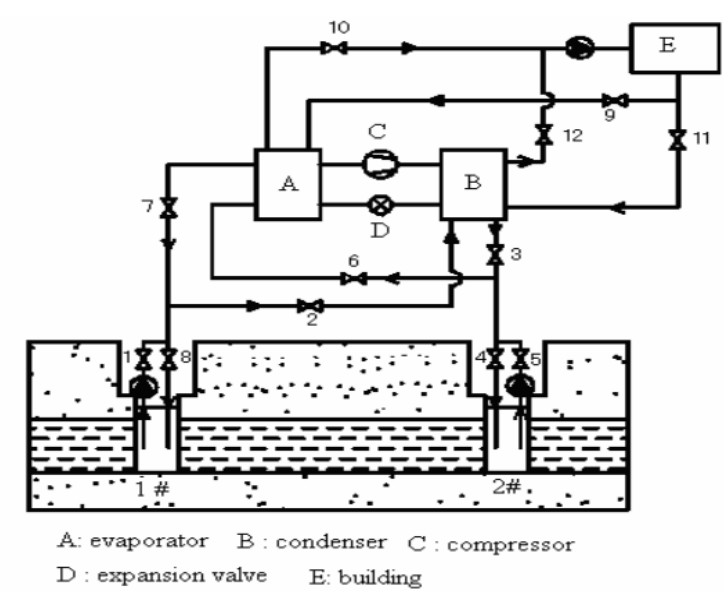

Figure 1. Diagram of Heat Pump Coupled Aquifer Thermal Energy Storage System.

\subsection{Energy storage efficiency definition}

Energy storage effect of aquifer thermal energy storage (ATES) of underground water heat pump system was evaluated by energy storage efficiency. So Energy storage efficiency was defined, which is the ratio of storing energy and total energy abstracted from underground. As formula is

$$
\eta=\frac{E_{s t}}{E} \times 100 \%
$$

In the formula, $E$ is the total energy of heat pump abstracted from underground, $\mathrm{J}$, it is calculated by formula (2).

$$
E=\int_{0}^{n} G c\left|t_{e x}-t_{r e}\right| d \tau=\sum_{0}^{n} G c\left|t_{e x}-t_{r e}\right|
$$

$G$ : Flux of underground water, $\mathrm{m}^{3} / \mathrm{d}$;

$c$ : specific heat of water, $\mathrm{J} /\left(\mathrm{kg} \cdot{ }^{\circ} \mathrm{C}\right)$;

$t_{e x}$ : extract water temperature, ${ }^{\circ} \mathrm{C}$

$t_{r e}$ : re-injected water temperature, ${ }^{\circ} \mathrm{C} ; n$ : running time, day:

Est is abstracted storing energy from underground, it is calculated by formula (3).

$$
E=\int_{0}^{n} G c\left|t_{e x}-t_{0}\right| d \tau=\sum_{0}^{n} G c\left|t_{e x}-t_{0}\right|
$$

$t_{0}$ : environment temperature of underground water ${ }^{\circ} \mathrm{C}$;

$\mathrm{m}$ : running time when abstracted water temperature higher (or lower) than the environment temperature of underground water.

In summer, $E_{c}$ is the heat energy storing in the water that temperature lower than the underground environment temperature, it can be considered as the cold energy stored in the aquifer, which is part of the re-injected cold energy in heating mode. Underground water is used as the heat sink of the heat pump, and absorbs heat of the heat pump system discharged and temperature rise, then the heated water is reinjected to underground and stored up around the inrejecting well, which will be supplied as higher temperature water for the heat pump in winter. It is reported (Sun 2011) that the high temperature and high pressure refrigerant gas enters the condenser from the compressor, the refrigerant releases heat to the cooling water, forms the high temperature and high pressure liquid, and causes the cooling water temperature to rise. The refrigerant is expanded into a low temperature and low pressure liquid through the expansion valve, and then enters into the evaporator to absorb the heat of the frozen water, at last evaporates into a low pressure steam, the temperature of the chilled water is reduced to get chilled water circulation in the evaporator. The principle diagram of the water source heat pump in summer is shown in Figure 2.

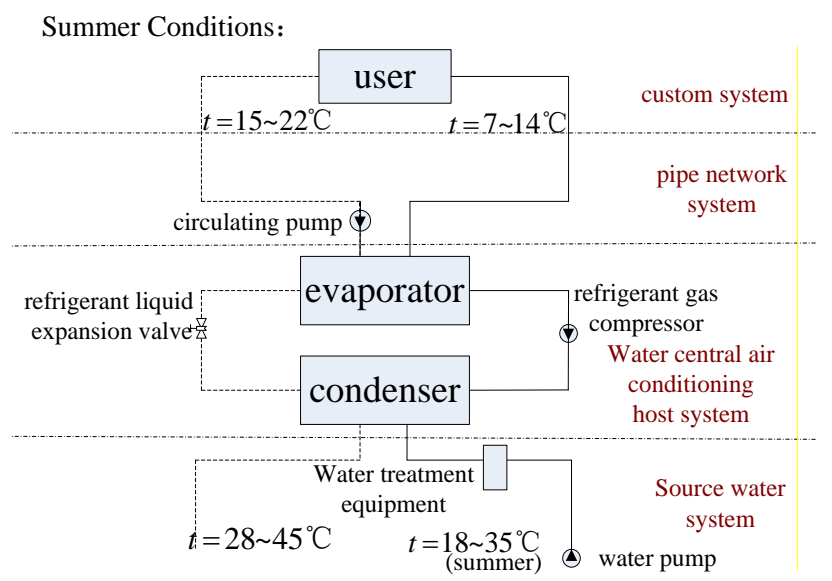

Figure 2. The principle diagram of the water source heat pump (summer).

In winter, underground water is used as heat source of the heat pump, heat pump absorbs heat from underground 
water for space heating, at the same time, underground water temperature is falling, the cold water is re-injected to underground and stored up around in-rejecting well, which will be used as the cool source of heat pump in summer (Figure 3). Based on Qu et al (2016) that refrigerant in the evaporator evaporates, and the heat in the water is absorbed, rear-load refrigerant condensing heat to raise the temperature, so as to enhance the temperature of airconditioned room.

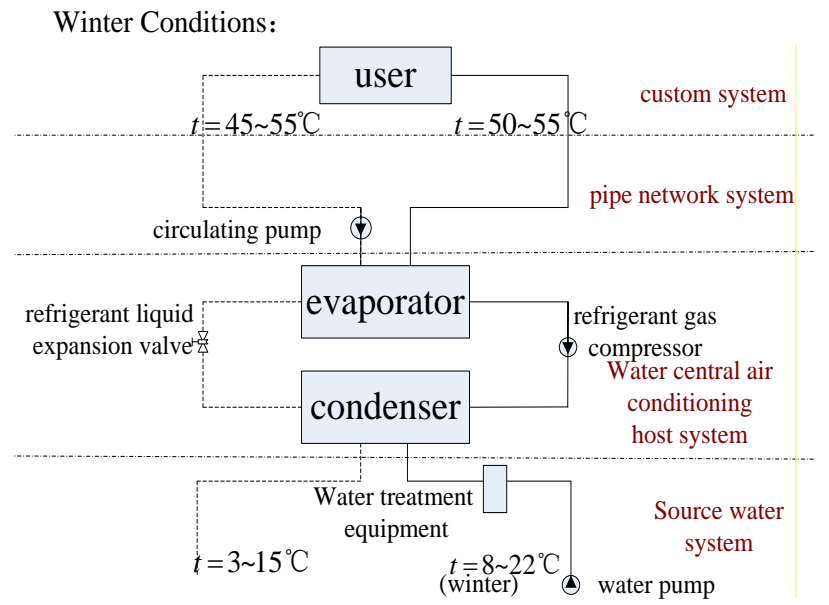

Figure 3. The principle diagram of the water source heat pump (winter).

\subsection{The advantages of water source heat pump}

(1) High efficiency and energy saving. Water source heat pump (WSHP) replaces cooling towers with underground constant temperature water, and has the characteristics of high efficiency energy-saving.

(2) Renewable energy technologies. As an efficient, energy-saving, environmental protection and sustainable development of advanced technology, water source heat pump is being widely used in air conditioning energy efficiency area.

(3) It is obvious of the benefit of environmental protection. Especially for simultaneously heating and cooling requirements of buildings, water source heat pump has obvious advantages.

\section{Mine underground thermal analysis and water source heat pump system design \\ 3.1 The operating conditions of Water source heat pump system}

It is reported (Perez et al 2016) that water source heat pump technology has many advantages, but it also needs the following conditions for security, stability, economic and efficient operation

(1) The reliable source of water. A reliable source of water is the basis of water source heat pump work. There are many different kinds of water in our earth, such as surface water, groundwater and rivers etc. At present, most of the water source heat pump using groundwater as low/high temperature heat source for heating/cooling. However, as the important resources of national, the use of groundwater in mining must be approval by relevant government departments, and should ensure the safety of groundwater recharge.

(2) Plenty of water. Water source heat pump needs much water to the cooling/heating load in working process. It should refer to the reasonable water hydro geological data before determining the solution

(3) Suitable water temperature. The temperature of the water is also the important factors which is influencing the water source heat pump. For the same unit, the energy provided by different temperatures of water is also different

(4) Good water quality. The water quality of water source heat pump units has certain requirements, If the water quality is not up to the requirements, it will be harmful to the host and its accessories, which will affect the operation of the system.

A metal mine in Jining area as an example. The application of water source heat pump technology is analyzed. Through the analysis and determination of water quality, the average water temperature of the mine is 42 , and the water inflow is $872 \mathrm{~m} 3 / \mathrm{h}$, which is suitable for the application of underground water source heat pump technology.

\subsection{Design parameters and heat load}

The mine heat pump air conditioning system is mainly used to extract energy from the water used for heating, cooling and heating water for workers and employees in the office and living facilities. Therefore, the design of selected air conditioning heat load of $450 \mathrm{~kW}$.

\subsection{System of cold heat source}

According to the detection of underground water quality, the water source heat pump unit with the model of MSRC44 is selected, and the heat is $573.1 \mathrm{~kW}$, providing $40^{\circ} \mathrm{C}$ hot water in winter.

\subsection{Reservoir energy saving design}

In view of the mine water temperature is high, in the design of an energy storage reservoir, the design capacity of $8 \mathrm{~m}$ * $\mathrm{m} * 6 \mathrm{~m}$ (length * width * depth), in the ground below the stone and the ground for the lawn. The main function of the energy saving reservoir is:

(1) To meet the water source heat pump unit at the maximum load of at least $6 \mathrm{~h}$;

(2) Sediment deposition;

(3) Adjust the water temperature of the underground water to meet the inlet temperature of the heat pump unit.

\subsection{Determination of total water quantity}

In winter, When the heat pump unit operates in the heating condition, the total amount of groundwater is:

$$
m_{g w}=\frac{Q_{c}}{C_{p}\left(t_{e x}-t_{r e}\right)} \times \frac{C O P-1}{C O P}
$$

where $m_{g w}$ : Air conditioning heat pump units in operation, the total water amount of groundwater; 
$C_{p}$ : The than constant pressure heat capacity of water

COP : Heat pump air conditioning can effect comparing, refers to the system heat pump units and the ratio of the motor input power。 Usually, $C p=4.19 \mathrm{~kJ}$ $/\left(\mathrm{kg} \cdot{ }^{\circ} \mathrm{C}\right)$

Heat pump has been selected, conditions can be determined in the $C O P$ value, according to the conditions, we can determine the heat load is $450 \mathrm{~kW}$, water temperature $t_{e x}=42{ }^{\circ} \mathrm{C}$, when hot water comes out surface, it's temperature will decline.

At this time, As long as the groundwater temperature value $t_{r e}$ of the heat exchanger is obtained, the $m_{g w}$ can obtained according to the type (4).

\section{Conclusions}

The application of water source heat pump in China is quite mature. The utilization of this technology can change the traditional heating mode of mine in Shandong Province and get rid of boiler. In the paper, the water source heat pump has sound operability and remarkable benefit of energy conservation and environment protection. The result shows that the system can reduce running expense and composite cost of mine. It saves $23 \%$ water per year, cuts down 3.303 million KW electric energy and reduces $4160 t$ emission of carbon dioxide. Besides, it reduces energy consumption of heating and refrigeration system, which facilitates the environment protection in mines. The effective use of water resources provides advantageous support for the construction of green mining areas and sustainable development. This technology not only economizes on energy and reduces discharge by taking full advantage of low-temperature waste heat in mine, but also possesses a better competitive power economically compared with the traditional heating mode by utilizing low-temperature waste heat and reducing loss of resources.

\section{Acknowledgment}

This work was supported by Cultivating fund of Excellent in Xi'an University of Architecture and Technology which title is "Study on the Intelligence Fusion of Multi-Source Heterogeneous Streaming Data and Warnings of Rock Mass Damage").

\section{References}

Blum, P., G. Campillo and T. Kölbel, 2011. Technoeconomic and spatial analysis of vertical ground source heat pump systems in germany. Energy, 6(5): 3002 3011 .

Hakkaki-Fard, A., P. Eslami-Nejad, Z. Aidoun and M. Ouzzane, 2015. A techno-economic comparison of a direct expansion ground-source and an air-source heat pump system in Canadian cold climates. Energy, 87: 49 $-59$.

Liu, X., 2009. Research of aquifer thermal energy storage system integrated underground water heat pump. Transactions - Geothermal Resources Council, 33: 516 -519 .

Ni, L., J. Dong, Y. Yao, C. Shen, D. Qv and X. Zhang, 2015. A review of heat pump systems for heating and cooling of buildings in china in the last decade. Renewable Energy, 84: 30 - 45.

Perez, E., S. Schneider and H.G. Havard, 2016. Controller, method of operating a water source heat pump and a water source heat pump. United States Patent Application, 20160265707.

Qu, M., J. Chen, L. Nie, F. Li, Q. Yu and T. Wang, 2016. Experimental study on the operating characteristics of a novel photovoltaic/thermal integrated dual-source heat pump water heating system. Applied Thermal Engineering, 94: 819 - 826.

Sarbu, I. and C. Sebarchievici, 2014. General review of ground-source heat pump systems for heating and cooling of buildings. Energy \& Buildings, 70(1): 441 454.

Sun, T., 2011. Analysis on energy consumption of the compound chiller (hot) water unit of evaporative cooling \& air source heat pump in summer. Refrigeration and Air-Conditioning. 